\title{
The Effect of Laboratory Work Style and Reasoning with Arduino to Improve Scientific Attitude
}

\section{Soka Hadiati}

Student of Postgraduate Program, Universitas Negeri Yogyakarta, Indonesia, sokahadiati@ikippgriptk.ac.id

\section{Heru Kuswanto}

Physics Study Program, Postgraduate Program, Universitas Negeri Yogyakarta, Yogyakarta, Indonesia, herukus61@uny.ac.id

\section{Dadan Rosana}

Sains Education Program, Postgraduate Program, Universitas Negeri Yogyakarta, Yogyakarta, Indonesia, danrosana@uny.ac.id

\section{Adi Pramuda}

Physics Education Program, IKIP-PGRI Pontianak, Indonesia. adipramuda@ikippgriptk.ac.id

This study aims to examine students' reasoning based on the model in each laboratory work style and find the effect on scientific attitude and student activity. This study uses a quantitative approach with the experimental method. The study was conducted in three classes with different lab work styles. Arduino and sensors were used as a measurement apparatus in Ohm's law experiments that will stimulate students' reasoning in each lab work. The measuring instruments consist of a scientific attitude scale, observation sheet, and worksheet. A descriptive statistical analysis was used to describe students' reasoning in the three laboratory work styles. The improvement of scientific attitude and activities were analyzed by normalized gain. The effects of the three types of lab work to scientific attitudes were analyzed by analysis of variance (ANOVA). The results show that the style of lab work gives rise to various students' reasoning. Observations show that many students solve problems in the experiment by reasoning to improve the measurement model. Problem-solving laboratory work is effective to improve activities and scientific attitudes. This study has succeeded to discover alternative concepts in the laboratory work with reasoning based on models.

Keywords: deductive, laboratory work, model-based reasoning, problem solving, technical skill

Citation: Hadiati, S., Kuswanto, H., Rosana, D., \& Pramuda, A. (2019). The Effect of Laboratory Work Style and Reasoning with Arduino to Improve Scientific Attitude. International Journal of Instruction, 12(2), 321-336. https://doi.org/10.29333/iji.2019.12221a 


\section{INTRODUCTION}

21-st century competency can be achieved if students have scientific skills, scientific attitudes, and critical thinking skills. The globalization requires students to have positive attitudes such as the willingness to accept and respect others, teamwork, honesty, skeptic, and high curiosity. Positive attitude has been developed in science learning as a scientific attitude. Pitafi \& Farooq (2012), Rubini \& Liliasari (2013), Lacap (2015), reported a lack of scientific attitudes of students at the junior high school level to university level, so it needs to be improved through the learning process.

Laboratory work is a part of science teaching that involves scientific processes and attitudes. Voronchenko, Klimenko \& Kostina (2015), found that learning in the laboratory produces not only professional competence, but a tolerant culture that demands cooperation strategies, respects dissent, and can encourage students to understand the difference in social phenomena. Eren, Bayrak, \& Benzer (2015), found that science experiments can develop positive attitudes and interests in science. Palic \& Pirasa (2012), showed that through laboratory activities the students will have a positive, creative and critical attitude in the experiment so as to obtain scientific results and understand the scientific rules. Students' attitudes have a significant influence on their thinking and actions (Alam, 2017). Attitudes formed through the learning of science determine the success of individuals.

Research in physics education has been focusing on physics learning in the classroom and rarely examine laboratory work. Wilcox \& Lewandowski (2016), stated that laboratory work involves students in authentic scientific practices, developing technical, laboratory skills, and collaboratively engaging with others in designing and building experiments, collecting and interpreting data, and communicating scientific content. Hamid et al., (2012) stated that in laboratory work it is necessary to harmonize the cognitive, affective, and psychomotor aspects. This shows the influence of physics learning techniques on students' scientific attitude. Laboratory activities can help students more easily acquire, integrate, and build knowledge (Sterna, Echeverria, Porta, 2017). Laboratory work facilitating students to plan and participate in investigations or take part in activities that enhance technical skills, laboratory skills, and cooperative skills. Laboratory work is very important because it can motivate students in learning through direct experience interacting with real phenomena, not through simulation.

Referring to Chiappetta \& Koballa (2010), laboratory work has five classifications according to their characteristics and objectives, i.e. scientific process skill, deductive or verification, inductive, technical skills, problem-solving. Style of lab work has its own characteristics that stimulate students' reasoning. Laboratory work cannot be separated from the model. The models are static, is a representation of phenomena. Static models become dynamic because of reasoning called model-based reasoning. In this study, the Arduino as a measurement tool is used to stimulate students' reasoning. This study aims to examine students' reasoning based on the model presented in each deductive, problem solving, technical skills laboratory work. Furthermore, it tries to find the influence on scientific attitude and student activities in laboratory work. Individuals with scientific attitudes will be able to: have a high curiosity, observe accurately, find causal 
relationships, be self-critical, show intellectual goodness, free from bias and prejudice, reject superstition, be honest, patience, diligence, fair, and thorough. (Rao, 2004). Scientific attitudes will form and change in line with individual development through the educational process. Scientific attitudes, reasoning, and student activities are very important to explore in the process of physics learning. The result of this study can be the basis for the development of better laboratory work in order to improve the students' achievement.

\section{LITERATURE REVIEW}

\section{Model-Based Reasoning}

Scientific models are directed to explain or to understand some aspects of the real world. Model as a surrogate object is a conceptual representation of the real thing (Hestenes, 1987). Model is an abstract representation and simplifying the system by focusing on the main features to explain and to predict scientific phenomena (Hestenes, 1987). The model is a visualization of something that cannot be directly observed through description. Models can help us understand how the phenomenon works. A scientific model is a conceptual mapped system in the context of a particular theory to a particular pattern in the structure or behavior of the physical system organization so that it can represent the intended pattern and possess a special function (Zwickl et al., 2015). Model as a final product derived from a cognitive activity that involves and requires reasoning is labeled as modeling (Jacobs \& Durandt, 2017).

Some researchers have defined the modeling with some different views. Modeling as a cyclical process involves (1) creating of a temporary model, (2) deriving from a series of interactive activities, (3) testing and refining continuously to correction or verification (Jacobs \& Durandt, 2017). The modeling process can be at any stage, combining different forms of language, such as computer programs, sketches, drawings, tables, and others. There are five major stages during the modeling process, i.e. understanding tasks, designing solution plans, planning, interpreting and verifying models, and presenting models (Zeytun, 2017). There are three main components for the modeling categories, namely physical system model, measurement model, and statistical analysis used to compare data and predictions (Zwickl et al., 2013). Physical system modeling means understanding basic physics ideas that go into predictive models, understanding model limitations, using models to make predictions, and revising models based on experimental results. Modeling of measurement systems is similar, but it involves understanding how physical phenomena connect data through measurement tools.

The basic idea of model-based reasoning put the physical models and phenomena are observed in action (Poll, 1999). Through action, the behavior will be observed and predicted. If there is a linking between observed and predicted behavior then the system is declared as consistent but if there is a mismatch, it should be tried for another model to explain the incompatibility. Static models can be dynamic because of the process of thinking and reasoning in laboratory work called model-based reasoning. Model-based reasoning is a generative representational change in science (Nersessian, 1999). ModelBased Reasoning has an important role in scientific discovery as it does in science 
learning (Nixon et al., 2016). Model-Based Reasoning in this research is the students' reasoning based on the measurement model and physical system in laboratory work.

\section{Style of Laboratory Work}

The physics learning process starts from understanding the concepts of qualitative followed by quantitative use of math concepts gradually (Retnawati et al., 2018). However, physics tends to be incomplete if it is not accompanied by experiments and laboratory work. Physical laboratory work has generally been recognized as an essential component of the undergraduate curriculum (Nixon et al., 2016; Wilcox \& Lewandowski, 2017). In university level, the dominant laboratory work is deductive which aims to verify the concept. The deductive laboratory consists of theoretical exposure, teacher's demonstrations, student's experiments, predictions, and discussions for conclusions (Chiappetta \& Koballa, 2010). Inductive laboratory work is one of the activities that have a purpose to obtain a concept that is not known yet. The inductive approach involves the construction of a theory in which the student must produce relevant principles by seeking common relationships behind a set of variables within a specific context (Lee \& Lo, 2014). Inductive laboratory activities consist of the presentation of theory at an early stage continued with experiments to prove the theory.

The success of laboratory work is mainly determined by the students' technical skills and processing skills in conducting experiments. Good laboratory techniques are important to support the success of laboratory activities. The difficulties that they experience in using practicum equipment also become problems in the learning of physics (Arista \& Kuswanto, 2018). Psychomotor and mental practice with laboratory procedures is important in improving students' ability to perform accurate and precise measurements. Technical skills are related to the use of tools when measuring and overcoming problems with broken tools.

The processing skills of science are related to the scientific inquiry. Harlen (1999), supports that science process skills are procedural, experimental and investigative skills or scientific ability. Scientific process skills are grouped into two, i.e. basic process skills and integrated process skills. According to Cigrik \& Ozkan (2015), basic process skills contain observation, measurement, classification, data recording, number, and spatial relationships. Integrated process skills cover controlling and identifying variables, hypotheses and tests, interpreting data, defining, designing as well as experimenting and modeling.

Activities in laboratory work cannot be separated from the problem-solving process. It is a scientific process that evolves from understanding the problem of evaluating solutions (Ozturk \& Guven, 2016). In the laboratory work of problem-solving, the students are invited to experience authentic inquiry experience. This approach is highly recommended because students are involved in managing their own learning and they can have a better understanding of what they should do. According to Lee (2015), the stages in problem-solving include understanding problems, designing plans, implementing plans, and evaluating. In addition, Ryan et al., (2016) clarify the problem- 
solving framework focuses on the problem, explains the physical system, creates a solution plan, executes the plan, and evaluates the answers.

\section{Scientific Attitudes}

The scientific attitude in this study is behavior that refers to one's willingness to use the scientific method. Scientific attitudes in this study include curiosity, teamwork, and critical attitude. Attitude is the response of the thought outcome through action. The process of thinking about what they observe and decide about how to act in reality leads to a critical attitude (Waterkemper, 2014). Critical attitude as a component of metacognition, characterized by dissatisfaction and it, thus, requires some explanation of conditions (Decamp \& Viennot, 2015). Critical attitudes are related to intellectual satisfaction seeking which is related to the impression of having a desire to understand complex topics to some extent which can be clearly identified (Harlen \& Qualter, 2004). This definition implies that a critical attitude is a reflection of the critical thinking ability which is performed in action.

Laboratory work requires good teamwork. Teamwork is a group of people who work together to achieve the desired goals (Southern Cross University, 2013). Teamwork has many benefits for students in the learning process. Teamwork is an important aspect that is so necessary for laboratory work that the laboratory work is expected to improve the ability of student cooperation. A shared understanding of the team's goals and culture will facilitate coordination within a team. Effective teams require a reliable communication process, with clear responsibilities and appropriate delegations. Individuals need to listen to each other and to collaborate to develop shared knowledge and communication for decision making.

Curiosity as a desire to know, see and gain experience by obtaining new information that is demonstrated by behavior (Litman \& Jimerson, 2004). The curiosity of the students can be seen through the daily learning activities. Referring Tieban et al., (2011), curiosity is shown with the desire to understand the new situation of sensing experience, paying attention to experience, and not hesitate to engage in new situations; while to complement knowledge (complexity) is demonstrated by activities of interpreting, exploring, and ambiguity.

\section{METHOD}

This study uses a quantitative approach with the experimental method. The study was conducted in 3 classes with different lab work styles. Class A applied deductive lab work, class B applied problem-solving lab work and class C applied technical skills lab work. The activities of the students in the laboratory work were identified by analyzing the worksheets. Students' reasoning based on a model in laboratory work was found by observation. The students were given a scale of scientific attitude before and after instruction to determine the improvement of scientific attitude. 


\section{Participant}

This study was conducted on the second semester of students of undergraduate physics education program in West Borneo consisting of 77 students. Ohm's law concepts were studied using Arduino and sensors as an electrical measuring apparatus.

\section{Instrument and Procedures}

Instruments in this study consist of a scientific attitude scale, observation sheet, and worksheet. Student reasoning was observed through student behavior during lab work using observation sheets. The observation sheet contains a list of things that will be observed by observers when observing student reasoning in overcoming Arduino problems in laboratory work activities. Student reasoning in laboratory work is divided into 4 categories, i.e. revision of the physical system apparatus, revision of physical system model, repair of apparatus measurement, and repair model measurement. Student activity was illustrated from the work of worksheet during lab work. The Worksheet is a guide containing the steps in completing the experiment. The steps of the activity that students must do on the worksheet consist of: reading theory, arranging tools, experiments, analyzing data, and making conclusions. Scientific attitude scale was given before and after learning. All instruments were validated by 7 experts and internal validity was calculated using Aiken V. Internal reliability was determined using interrater reliability. External validity of the scale of scientific attitudes was determined by Winsteps program which refers to the Rasch Theoretical Model. The results of validity and reliability calculations are as shown in Table 1.

Table 1

Validity and Reliability Instruments

\begin{tabular}{llllll}
\hline Type of data & Instrument & Type of validity & Validity & Reliability & Category \\
\hline Scientific & Scientific & External & 0.90 & 0.92 & High \\
\cline { 2 - 6 } attitude & attitude scale & Internal & 0.81 & 0.80 & High \\
\hline Reasoning & Observation & Internal & 0.92 & - & High \\
\hline Activities & Worksheet & Internal & 0.89 & - & High \\
\hline
\end{tabular}

According to Table 1, all instruments have high validity and scientific attitude scale has high reliability. This indicates that all instruments used have met the eligible criteria.

\section{Data Analysis}

The descriptive statistical analysis was used to describe students' reasoning and activities during their work at the three laboratory work styles. Statistical tests have been used to know lab work's significance of scientific attitudes and activities. The effects of the three types of lab work on scientific attitudes were analyzed by analysis of variance (ANOVA). The improvement of scientific attitude was determined with the formula of gain as follows:

$<g>=\frac{S_{\text {pre }}-S_{\text {post }}}{100 \%-S_{\text {pre }}}$ 
The criteria for gain index was determined according to Hake (1998), with $\mathrm{g}>0.70$ high category; $0.30<\mathrm{g}<0.70$ medium category; and $\mathrm{g} \leq 0.30$ low category.

\section{FINDINGS}

Several previous studies have used Arduino as an electric measurement tool, i.e. Atkin (2016, 2017), Pereira (2016), Zachariadou, Yiasemides and Trougkakos (2012) and Kubinova and Slegr (2017). However, the research was limited to the development of electrical measuring devices in observing students' reasoning. In this study, we present a set of Arduino and sensors based on Ohm's law as a model representing electrical phenomena. Figure 1 presents the application of Arduino and sensors as an AVOmeter or multitester to measure current and voltage. The Arduino used is Arduino Uno R3, which is a microcontroller board based on the ATmega328P. In this experiment, the circuit consists of a resistor connected to the battery as a voltage source. Arduino is connected with a current sensor ACS712 in order to measure electric current, while to measure the voltage, the Arduino is connected to a voltage sensor module. Arduino board connected to the computer and then the program code is entered. If the program code is correct, the correct value will be displayed on the computer.

Experimental apparatus as in Figure 1 is given to each group of students in deductive lab work, problem-solving, and technical skills. The learning phase begins by reading the theory guide, arranging tools and materials, experiments, analyzing data and making conclusions. In deductive lab work, students are directed to prove Ohm's Law. In this laboratory work style, students must be able to obtain experimental results in accordance with Ohm's law theory which states that the current in a resistor is proportional to the potential difference if the temperature is constant. Meanwhile, in lab work problemsolving style, students are focused on solving problems that arise during the experiment. Students are given a set of experimental tools that have been designed to have certain malfunctions. This is indicated by the measurement value of the current and voltage that is not correct due to an error in connecting the cable and incomplete program syntax. Therefore, in this lab work style students are directed to find solutions. In lab work technical skills style, students are required to be skilled at operating sensors and Arduino. Students use the experiment tools carefully and repeatedly so that they are able to get accurate data, read the board diagram correctly, and modify the Arduino programming code. 


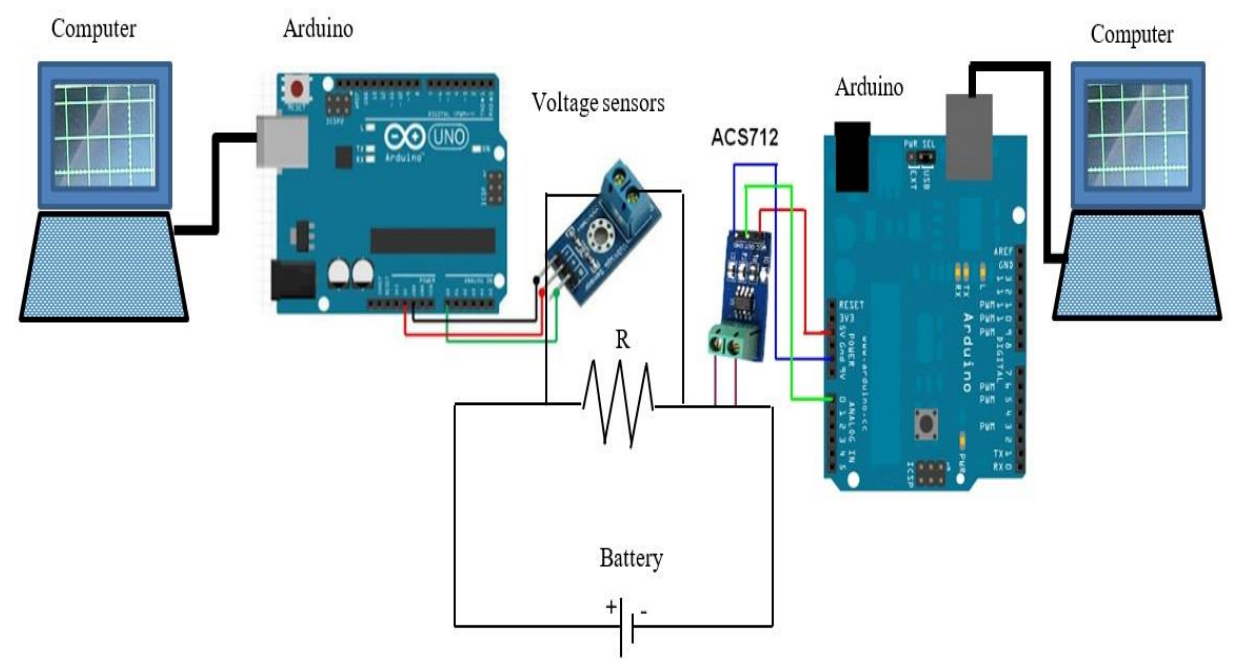

Figure 1

Ohm's Law series of experiments using Arduino

In conducting experiments with Arduino through the deductive, problem-solving, and technical skills lab work, students will encounter various problems especially when Arduino and sensors do not show precise measurements, this will stimulate the students' reasoning in obtaining solutions. Each student can have a lot of reasoning not tied to just one kind of reasoning. According to the observations, the intensity of student reasoning in four categories was obtained on deductive, problem solving, and technical skills laboratory work presented in Figure 2.

Figure 2 presents the varied reasoning in each of the laboratory sections. In deductive and problem-solving laboratory work, students are more likely to reason by repair the measurement model with an average percentage of $35 \%$ and $43 \%$. Student reasoning is shown by analyzing the measurement model by improved the experimental scheme. In deductive laboratory work, $29 \%$ of the students repair the Arduino measurement device, by checking whether the Arduino device was working properly or not and fixed the Arduino device. In problem-solving lab work, $32 \%$ of the students rechecked the physical system model by analyzing the equations used in the theory. In the laboratory work of technical skills, $47 \%$ of the students tend to revise the physical system devices through the activities of looking at experimental devices related to the theory. $12 \%$ the students revised the physical system model and $10 \%$ of the students repair the measurement device. 


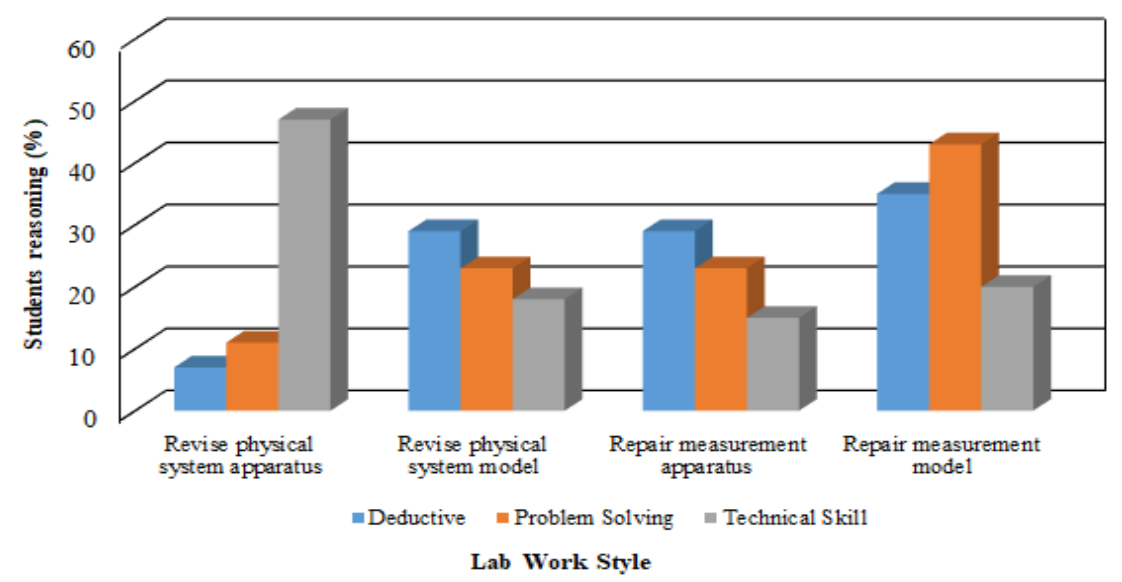

Figure 2

The intensity of student reasoning in four categories on deductive, problem solving, and technical skills laboratory work

In the three styles of lab work, few students revised the physical system model and repair the measurement tools. When getting a problem, students tend to refine the measurement model by reading the theory again and matching it with the experimental device used. This contrasts with the findings of Frazer et al. (2016) and Zwickl et al. (2015). Frazer et al. (2016), indicate that when troubleshooting occurs, students tend to replace suspected altered tools. In line with that, Zwickl et al. (2015) indicate that students are more likely to be revision measurement tools. The students have different reasoning depending on his academic ability. Students' academic abilities are related to the skills of thinking in solving problems.

The subject matter and experimental tools used have an important role in students' reasoning. Different experimental tools will give rise to different reasons. This study is in line with Frazer et al (2016) and Zwickl et al. (2015), in reviewing students' reasoning in electrical material. However, this research uses Arduino as an electric measuring device, while previous research only used basic electrical measuring devices such as multimeters and oscilloscopes. Arduino with sensors have as many benefits at a low cost, so it is well applied in learning and is able to train students in digital learning to prepare themselves for the 4.0 industrial revolution.

Laboratory work involved students to take part in scientific activities. The activities involve students in scientific investigations by directing students in asking for a solution, proposing problem-solving solutions, designing experiments, making predictions, observing, organizing data, providing explanatory patterns, and so on. The activities students show during the lesson with the different styles of laboratory work are presented in Figure 3. 


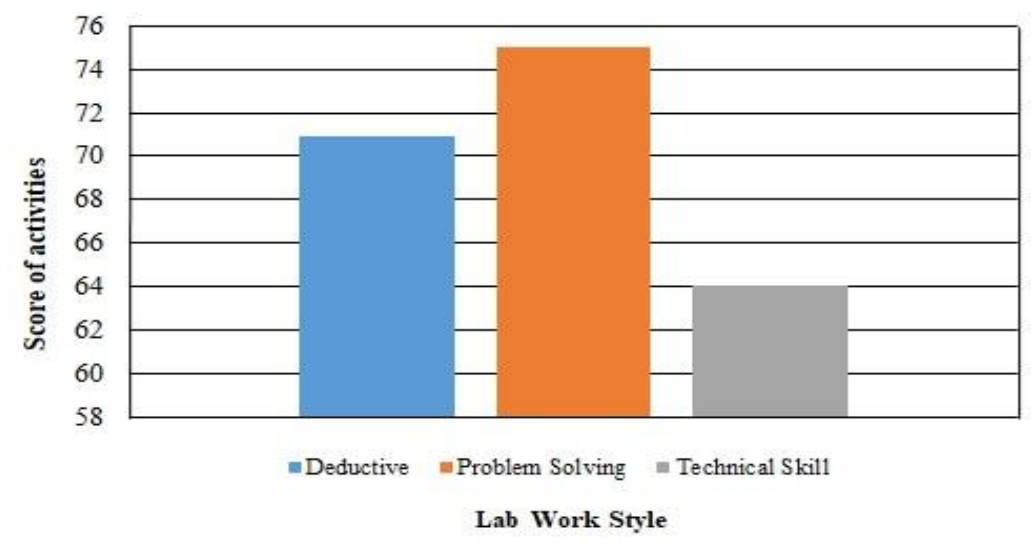

Figure 3

Students' activities in three styles of lab work

Each laboratory work has its own characteristics that give rise to typical activities during the spin. Deductive laboratory work activities are characterized by proving theory through experimentation. In the laboratory lab problem solving, there are activities to identify problems, investigate, and experiment to solve problems. In the lab work of technical skills, the activity is based on the correct measurement and measurement tools improvement. The average score of the activities obtained from the worksheet is known that the laboratory problem-solving work successfully stimulates the highest student activity.

This is supported by previous researchers, Lee (2015), Mataka et al. (2014), and Buteler and Coleoni (2016), which shows that problem solving is effectively applied in mathematics and science learning. Their research indicates that the application of problem-solving improves student learning outcomes, both on affective, cognitive, and psychomotor learning outcomes. In this study, problem-solving involving students from understanding the problem in evaluating the solution has an impact on the high activity of students.

The goal of laboratory work is to improve students' cognitive, affective, and psychomotor cognition. Laboratory work involves scientific processes and attitudes. Activity in laboratory work can give students an understanding of how scientists work so it can influence the students' attitudes toward the scientist's efforts. Attitudes are actions that reflect feelings and understanding. The cultivation of scientific attitudes in laboratory work continuously will be able to shape the character and attach to the student self. Figure 4 presents the students' scientific attitude scores in three styles of lab work and their improvement.

Figure 4 presents the improvement of scientific attitude after laboratory work. The laboratory work is the highest problem-solving in improving scientific attitude with a gain of 0.6. This shows that laboratory problem-solving work can improve scientific 
attitude, which consists of critical attitude, curiosity, and cooperation. This is supported by the research of Chao et al., (2017) which report that problem-solving activities can lead to a cyclical attitude that is critical and curiosity demonstrated through initiative and willingness to learn. Gustafsson et al., (2014) shows that problem-solving activities can train the scientific attitude of good cooperation in groups of students in the physics department.

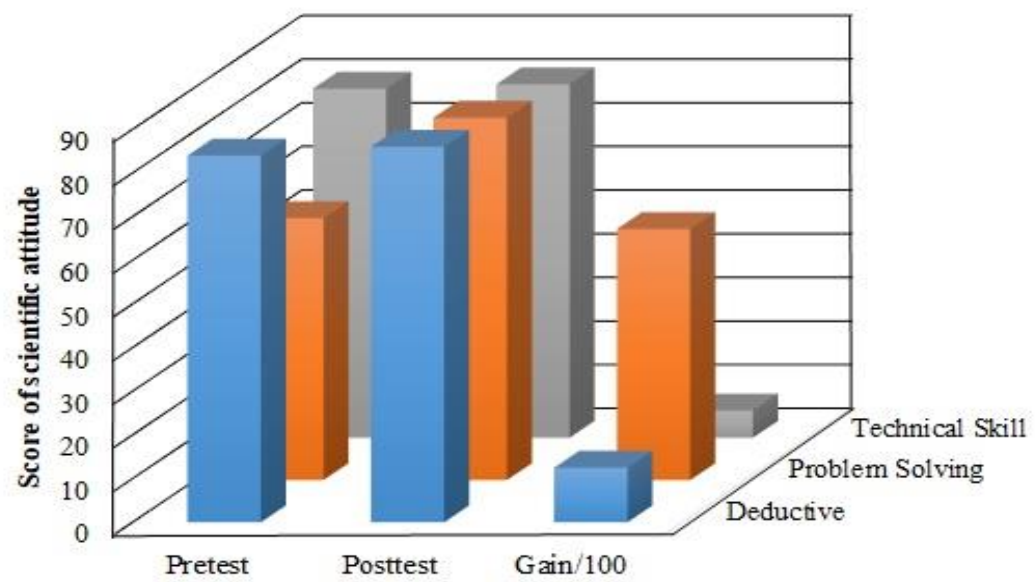

Figure 4

Scientific Attitude in Laboratory Work

Statistic test is used to know the influence of three styles of laboratory work on scientific attitude and student activity. Data on scientific attitudes and student activities in each lab work were standardized and normalized as in Table 1 and Table 2. Normality and homogeneity tests as a prerequisite analysis were presented below.

Table 1

The Result of Normality Data

\begin{tabular}{cllll}
\hline \multirow{2}{*}{$\begin{array}{c}\text { Variable } \\
\text { Dependent }\end{array}$} & \multirow{2}{*}{ Variable Independent } & \multicolumn{3}{l}{ Tests of Normality (Kolmogorov-Smirnov) } \\
\cline { 2 - 5 } & & Statistic & df & Sig. \\
\hline \multirow{3}{*}{ Attitude } & Deductive & 0.150 & 23 & 0.194 \\
\cline { 2 - 5 } & Problem Solving & 0.108 & 25 & 0.200 \\
\cline { 2 - 5 } & Technical Skill & 0.146 & 29 & 0.115 \\
\hline \multirow{3}{*}{ Activities } & Deductive & 0.467 & 23 & 0.000 \\
\cline { 2 - 5 } & Problem Solving & 0.345 & 25 & 0.000 \\
\cline { 2 - 5 } & Technical Skill & 0.300 & 29 & 0.000 \\
\hline
\end{tabular}

Table 2

Results of Homogeneity Data

\begin{tabular}{lllll}
\hline Variable Dependent & Levene Statistic & df1 & df2 & Sig. \\
\hline Attitude & 0.255 & 2 & 74 & 0.776 \\
\hline Activities & 5.156 & 2 & 74 & 0.008 \\
\hline
\end{tabular}


The data of scientific attitude is normal and homogeneous as shown in Table 1 and 2 . Parametric tests with analysis of variance (ANOVA) are used, while activity data were analyzed by the Kruskal Wallis test because it was not normal and not homogeneous. The statistical test results are presented in Table 3 and Table 4.

Table 3

Results of ANOVA Test

\begin{tabular}{llllll}
\hline & Variable & df & Mean Square & F & Sig. \\
\hline Attitude & Between Groups & 2 & 57.012 & 1.324 & 0.272 \\
\hline Within Groups & 74 & 43.073 & & \\
\hline Total & 76 & & & \\
\hline
\end{tabular}

Table 4

Results of Kruskal Wallis test

\begin{tabular}{llll}
\hline Variable & Chi-Square & Df & Asymp. Sig. \\
\hline Activities & 28.554 & 2 & 0.000 \\
\hline
\end{tabular}

ANOVA test in Table 3 indicated sig $>0.05$ so it is known there is no influence of three styles of lab work on scientific attitude. This suggests that all laboratory work has the same effect on the improvement of scientific attitudes. Laboratory work allows students to plan and participate in investigations or take part in activities that can improve scientific attitudes. Deductive, problem solving and technical skills lab work is capable of inculcating scientific attitude. This is in line with the results of research of Ekawati (2017) reporting that scientific attitudes arise in every phase of physics learning. However, it is different with the result of Çibik \& Yalcin (2011) which show the influence of physics learning technique to students' scientific attitude. The study shows that different physics learning techniques will have an influence on students' scientific attitudes. Referring to the weakness of this study, for further research, it is recommended that scientific attitudes are measured more deeply by reviewing other aspects, such as honesty, and patience.

There is an influence between deductive laboratory work, problem-solving, and technical skills on student activities. Different style lab work will lead students into different activities. Problem-solving laboratory work is most influential in increasing student activity. Problem-solving is a scientific process that evolves from understanding the problem of evaluating solutions (Ozturk \& Guven, 2016). In the laboratory work of problem-solving students are invited to experience authentic inquiry experience. This approach is highly recommended because students are involved in managing their own learning and they better understand what they should do.

\section{CONCLUSION}

The activities of laboratory work involves the students in scientific investigations by directing students in asking for a solution, proposing problem-solving solutions, designing experiments, making predictions, observing, organizing data, and providing explanatory patterns. The style of lab work brings up to various students' reasoning. Most of the student reasoning to repair the measurement model was improved by the experimental scheme. Students tend to re-ignore the theory and match it with the 
experimental devices used. Different style lab work will lead students into different activities. The laboratory work of problem-solving is effective to improve activities and scientific attitudes. The type of laboratory work has an influence on student activity. However, there is no effect of style of lab work on scientific attitude. This research has succeeded to find the best laboratory work that can improve a student's attitude and activity.

\section{ACKNOWLEDGMENTS}

This research is supported by the Ministry of Research Technology and the Higher Education Republic of Indonesia with contract number 010/L.202.103/PDD/III/2018.

\section{REFERENCES}

Alam, Q. (2017). Impact of the school outreach tour program of citizens archive of Pakistan on students' perceptions and attitudes. International Journal of Instruction, 10(1), 289-306. doi: 10.12973/iji.2017.10118a.

Arista, F. S., \& Kuswanto, H. (2018). Virtual physics laboratory application based on the android smartphone to improve learning independence and conceptual understanding. International Journal of Instruction, 11(1), 1-16. https://doi.org/10.12973/iji.2018.1111a.

Atkin, K. (2016). Using the Arduino with MakerPlot software for the display of resonance curves characteristic of a series LCR circuit. Physics Education, 51(6) 065006. doi:10.1088/0031-9120/51/6/065006

Atkin, K. (2017). Using the Arduino with MakerPlot software for the display of electrical device characteristics. Physics Education, 52(6) 065007. https://doi.org/10.1088/1361-6552/aa83e7

Buteler, L and Coleoni, E. 2016. Solving problems to learn concepts, how does it happen? A case for buoyancy. Physical Review Physics Education Research, 12(2) 020144, 1-12. doi: 10.1103/PhysRevPhysEducRes.12.020144.

Chao, J.Y., Tzeng, P.W., \& Po, H.Y. (2017). The study of problem-solving process of e-book PBL course of Atayal senior high school students in Taiwan. EURASIA Journal of Mathematics Science and Technology Education, 13(3), 1001-1012. doi: 10.12973/eurasia.2017.00654a.

Chiappetta, E.L \& Koballa T.R. (2010). Science instruction in the middle and secondary schools developing fundamental knowledge and skill. USA: Pearson.

Cibik, S \& Yalcin, N. (2011). The effect of teaching the direct current concept with analogy technique to the attitudes of science education students towards physics. Procedia Social and Behavioral Sciences, 15, 2647-2651. doi: 10.1016/j.sbspro.2011.04.163. 
Cigrik, E \& Ozkan, M. (2015). The investigation of the effect of visiting science center on scientific process skills. Procedia - Social and Behavioral Science 197, 1312 - 1316. doi: 10.1016/j.sbspro.2015.07.405.

Decamp, N \& S Viennot, L. (2015). Co-development of conceptual understanding and critical attitude: Analyzing texts on radiocarbon dating. International Journal of Science Education, 37(12), 2038-2063. doi: 10.1080/09500693.2015.1061720.

Ekawati, E.Y. (2017). A model of scientific attitudes assessment by observation in physics learning based scientific approach: case study of dynamic fluid topic in high school. Journal of Physics: Conf. Series 795, 1-9. doi:10.1088/1742-6596/795/1/012056.

Eren, C. D., Bayrak, B. \& Benzer, K.E. (2015). The examination of primary school students' attitudes toward science course and experiments in terms of some variables. Procedia - Social and Behavioral Sciences 174, 1006-1014. https://doi.org/10.1016/j.sbspro.2015.01.1245.

Frazer, D.R., Bogart, K.L. \& Stetzer, M.R. (2016). Investigating the role of modelbased reasoning while troubleshooting an electric circuit. Physical Review Physics Education Res, 12, 010137, 1-20. doi: 10.1103/PhysRevPhysEducRes.12.010137.

Gustafsson, P., Jonsson, G. \& Enghag, M. (2014). The problem-solving process in physics as observed when engineering students at university level work in groups. European Journal of Engineering Education, 40(4), 380-399. doi: 10.1080/03043797.2014.988687.

Hake, R. R. (1998). Interactive-engagement versus traditional methods: a six-thousandstudent survey of mechanics test data for introductory physics courses. American Journal of Physics Research. 66(1), 64-74. doi: 10.1119/1.18809.

Hamid, R., Baharom, S., \& Hamzah, R. (2012). Assessment of psychomotor domain in materials technology laboratory work. Procedia - Social and Behavioral Sciences, 56, 718-723. https://doi.org/10.1016/j.sbspro.2012.09.708.

Harlen W \& Qualter A. (2004). The teaching of science of primary schools. London: David Fulton Publisher.

Harlen, W. (1999). Purposes and procedures for assessing science process skills. Assessment in Education, 6(1), 129-144. http://dx.doi.org/10.1080/09695949993044.

Hestenes, D. (1987). Toward a modelling theory of physics instruction. American Journal of Physics, 55(4). doi: 10.1119/1.15129.

Jacobs, G.J \& Durandt, R. (2017). Attitudes of pre-service mathematics teachers towards modelling: a south African inquiry. EURASIA Journal of Mathematics Science and Technology Education, 13(1), 1-84. doi: 10.12973/eurasia.2017.00604a.

Lacap, P. (2015). The scientific attitudes of students major in science in the new teacher. Asia Pacific Journal of Multidisciplinary Research, 3(5), 7-15. 
Kubínová, S and Šlégr, J (2015). Physics demonstrations with the Arduino board. Physics Education, 50(4), 472-474. doi:10.1088/0031-9120/50/4/472.

Lee, V \& Lo, A. (2014). From theory to practice: Teaching management using films through deductive and inductive processes. The International Journal of Management Education, 12, 44-54. http://dx.doi.org/10.1016/j.ijme.2013.05.001.

Lee, C.I. (2017). An appropriate prompts system based on the polya method for mathematical problem-solving. EURASIA Journal of Mathematics Science and Technology Education,13(3), 893-910. doi: 10.12973/eurasia.2017.00649a.

Litman, J.A \& Jimerson, T.L. (2004). The measurement of curiosity as a feeling deprivation. Journal of Personality Assessment 82(2), 147-157. doi: 10.1207/s15327752jpa8202_3.

Mataka, L.M, Cobern, W.W, Grunert, M, Mutambuki J, \& Akom, G. (2014). The effect of using an explicit general problem-solving teaching approach on elementary preservice teachers' ability to solve heat transfer problems. International Journal of Education in Mathematics Science and Technology, 2(3), 164-174.

Nersessian, N.J. (1999). Model Based-reasoning in Scientific Discovery. New York: Kluwer Academic/Plenum Publishers.

Nixon, RS., Godfrey, TJ., Mayhew, NT., Wiegert, C.C. (2016). Undergraduate student construction and interpretation of graphs in physics lab activities. Physical Review Physics Education Research, 12(1), 010104, 1-19. doi: 10.1103/PhysRevPhysEducRes.12.010104.

Ozturk, T \& Guven, B. (2016). Evaluating students' beliefs in problem solving process: A case study. Eurasia Journal of Mathematics, Science \& Technology Education, 12(2), 411-429. doi: 10.12973/eurasia.2016.1208a.

Palic, G. \& Pirasa, N. (2012). A study of pre-service teachers' tendency for imprudent behavior and physics laboratory attitudes. Procedia - Social and Behavioral Sciences 47, 823 - 828. doi: 10.1016/j.sbspro.2012.06.742.

Pereira, N S A. (2016). Measuring the RC time constant with Arduino. Phys. Educ, 51(6), 065007. doi:10.1088/0031-9120/51/6/065007.

Pitafi, A.I \& Farooq, M. (2012). Measurement of scientific attitude of secondary school students in Pakistan. Academic Research International, 2(2), 379-392.

Poll, S., Iverson, D. \& Patterson-Hine. (2003). Characterization of model-based reasoning strategies for use in IVHM architectures. Proceedings of SPIE - The International Society for Optical Engineering. doi: 10.1117/12.487219.

Retnawati, H., Arlinwibowo, J., Wulandari, N.F. \& Pradani, R.G. (2018). Teachers' difficulties and strategies in physics teaching and learning that applying Mathematics. Journal of Baltic Science Education, 17(1), 120-135.

Rao, D.B. (2004). Scientific attitude, scientific aptitude, and achievement. Discovery 
Publishing House: New Delhi.

Rubini, B and Liliasari. (2013). Basic natural sciences contribution for scientific attitude development and values of life. International Journal of Science and Research, 2(5), 465-468. doi: 10.1088/1742-6596/1028/1/012206.

Ryan, Q. X., Frodermann, E \& Heller, K., et al. (2016). Computer problem-solving coaches for introductory physics: Design and usability studies. Physical Review Physics Education Research 12(1), 010105. doi: 10.1103/PhysRevPhysEducRes.12.010104.

Southern Cross University. (2013). Teamwork guide. Australia: Southern Cross University.

Tieban, R., Bekker, T \& Schouten, B.A.M. (2011). Curiosity and interaction: making people curious through interactive system. Proceedings of British Computer Society Conference on Human-Computer Interaction (BCSHCI): 361-370.

Waterkemper, R., do Prado, ML., Medina, JLM. \& Reibnitz, K. S. (2014). Development of critical attitude in fundamentals of professional care discipline: A case study. Nurse Education Today 34: 581-585. http://dx.doi.org/10.1016/j.nedt.2013.07.015.

Wilcox, B.R \& Lewandowski, H.J. (2016). Open-ended versus guided laboratory activities: Impact on students' beliefs about experimental physics. Physical Review Physics Education Research 12, 020132, 1-8. doi: 10.1103/PhysRevPhysEducRes.12.020132.

Wilcox, B.R \& Lewandowski, H.J. (2017). Students' epistemologies about experimental physics: validating the Colorado learning attitudes about science survey for experimental physics. Physical Review Physics Education Research,12(1), 010123, 111. https://doi.org/10.1103/PhysRevPhysEducRes.13.020110.

Zeytun, A.S., Cetinkaya, B. \& Erbas, A.K. (2017). Understanding prospective teachers mmathematical modelling processes in the context of a mathematical modelling course. EURASIA Journal of Mathematics Science and Technology Education, 13(3), 691-722. doi 10.12973/eurasia.2017.00639a.

Zwickl，B.M，Hu，D, Finkelstein, N. \& Lewandowski, H.J (2015). Model-based reasoning in the physics laboratory: Framework and initial results. Physics Education Research, 11(2), 020113, 1-12. doi: 10.1103/PhysRevSTPER.11.020113.

Zwickl, B.M., Finkelstein, N. \& Lewandowski, H.J. (2013). The process of transforming an advanced lab course: Goals, curriculum, and assessments, American Journal of Physics Research, 81(1), 1-25. http://dx.doi.org/10.1119/1.4768890.

Zachariadou, K, Yiasemides, K and Trougkakos, N. (2012). A low-cost computercontrolled Arduino-based educational laboratory system for teaching the fundamentals of photovoltaic cells. Eur. J. Phys, 33, 1599-1610. doi:10.1088/0143-0807/33/6/1599 